\title{
Maintaining Quality Online: Piloting an Online Language Course for Immigrants in Finland
}

\author{
Miia Karttunen ${ }^{1}\left[\right.$ and Sirpa Juusola ${ }^{2, *}$ \\ 1 Department of Common Studies, South-Eastern Finland University of Applied Sciences, 45100 Kouvola, \\ Finland; miia.karttunen@xamk.fi \\ 2 Department of Common Studies, South-Eastern Finland University of Applied Sciences, 57100 Savonlinna, \\ Finland \\ * Correspondence: sirpa.juusola@xamk.fi
}

Received: 17 December 2018; Accepted: 20 April 2019; Published: 22 April 2019

\begin{abstract}
Finland's educational system has aroused the interest of educational researchers worldwide. Teaching and learning with information and communication technologies (ICT) is one of the major methodologies in the present Finnish educational discourse. Feedback and assessment are questions of course design in online learning. This paper discusses and illustrates how to plan an online course for a higher education preparatory program in Finland by using digital methods with a focus on maintaining quality in the processes of feedback and evaluation. This paper also introduces and reflects recently published quality criteria that are recommended to be used in the design of online courses.
\end{abstract}

Keywords: higher education; preparatory education; immigrant; quality; feedback

\section{Introduction}

This article examines the processes of feedback and assessment in online language courses in higher education institutions (HEI). While online learning gathers bigger groups, teachers and institutions are forced to pay attention to the effectiveness and quality of the processes of evaluation and feedback since they have a significant impact on learning. A course should be structured so that it allows the students and teachers to reflect on their performance and to compare it with the set goals and to utilize the feedback they receive during the course.

This article discusses how to maintain quality in the processes of feedback and assessment in online language courses. The discussion is a part of the Finnish project "Getting ready-A higher education preparatory program for immigrants" which aims to develop the national recommendations for online training courses for immigrants who wish to apply to study in higher education institutions. The project group has drawn up a proposal for the preparatory program qualifications, and the first implementation of the piloting preparatory course starts in April 2019.

The article also introduces the Finnish education system and the reasons why Finland's educational system has aroused the interest of educational researchers worldwide. Teaching and learning with information and communication technologies (ICT) is one of the major methodologies in the present Finnish educational discourse. At the moment, Finnish HEIs are competing in many fields, and teaching and learning technologies are often mentioned in the institutions' profiles. Due to geographical reasons, our institution, the South-Eastern Finland University of Applied Sciences (later Xamk), has developed into one of the leading HEIs for online teaching in Finland.

The concepts of quality and feedback in higher education (particularly quality) are defined from the viewpoint of online learning. This brief theoretical background is reflected in relation to the 
recent quality criteria for online implementations which were published for Finnish HEIs and other educational institutions in order to build high quality online courses.

Finally, the article presents our ongoing work in the project "Getting ready-A higher education preparatory program for immigrants". We study some learning principles and quality criteria that should be taken into account when creating online implementations. Our article is not a traditional research article. Instead, we would like to open discussion on the efficiency and future development of the selected principles.

\section{Online Learning in Finland}

The term online learning is used interchangeably with several terms, like e-learning, digital learning, virtual learning, cyberlearning, or even distance learning in specific contexts. Network and communication technologies provide language learning solutions for delivering instructions to learners in remote locations. Online learning means that the learning process is instructed via computer networks. This provides opportunities to reach people in distant geographical locations, as well as globally. (Lim et al. 2007)

Lim et al. (2007) bring together several studies in order to compare instructional outcomes and learner satisfaction in online learning processes. Several studies (e.g., Otte and Benke 2006; Pardere 2012) suggest that online learning can offer more beneficial and flexible learning modes compared to traditional face-to-face mode. However, there are also certain obstacles which can endanger adequate learning results (see e.g., Fontaine 2002; Oh and Lim 2005; Hong and Samimy 2010). In order to achieve sufficient results in online learning, a learner is expected to be motivated and active and have a good command of learning skills. The learning outcomes are better and the development is deeper if a learner has strong engagement and self-motivation for the online learning process. A sense of belonging and a community have influence on learner satisfaction and learning effectiveness. Since online learning processes lack genuine face-to-face interaction between a teacher and a learner, it is important to create a sense of presence and a feeling of immediacy when using the resources of communication technologies. However, according to Lim et al. (2007), no significant differences were found in learning outcomes between online and blended delivery methods.

Pardere (2019) presents varying definitions for the term Blended Learning (BL). BL refers to the blend of traditional face-to-face teaching environment and online learning environment together with ICT-mediated teaching or computer-assisted learning (CAL). The term blended learning has been used synonymously with hybrid learning, hybrid instruction, mixed mode learning and technology-mediated learning or technology enhanced learning (Wang et al. 2015). In the context of Finnish education, BL often occurs when using the flipped classroom method.

In BL courses, online and other modalities are used side by side and are connected (Staker and Horn 2012). According to Wang et al. (2015), BL is a very complex system which consists of six separate but interacting subsystems: the learner, the teacher, the technology, the content, the learning support, and the institution. In the case of language studies, we may give a definition that BL combines computer-assisted language learning (CALL) technologies and face-to-face interaction. L2 education can be used to support efficient learning. BL can be beneficial, e.g., in promoting learners' motivation and empowering learner autonomy, but L2 researchers are not convinced that BL implementations always accomplish the intended benefits (Hong and Samimy 2010; Pardere 2012).

This article focuses on the Finnish preparatory online program for immigrants, and in this program, the courses are not implemented with BL methods, only the CALL mode (i.e., web-based teleconferencing and online instruction via web-based learning environments/platforms) is used, but the core of the problem is the same: We are trying to support the learners' motivation and empowered attitude, but the teacher can't be sure whether the learner reaches the intended outcomes. In online courses, the lack of real face-to-face interaction may blur the teacher's ability to observe the learner's actual level of competence and attitude. Hong and Samimy (2010) study shows that the learners' attitudes towards CALL are influenced by the learners' general computer skills, daily hours of internet 
use or daily hours of L2 studies on the internet, gender, age and prior language learning experiences. A positive attitude creates positive learning results and positive results improve attitudes.

With a population of 5.5 million and an area of 338,440 square kilometers, the population density in Finland is quite low, being 18.1 inhabitants per $\mathrm{km}^{2}$. About $25 \%$ of the population lives in the Helsinki metropolitan area. (Figure 1).

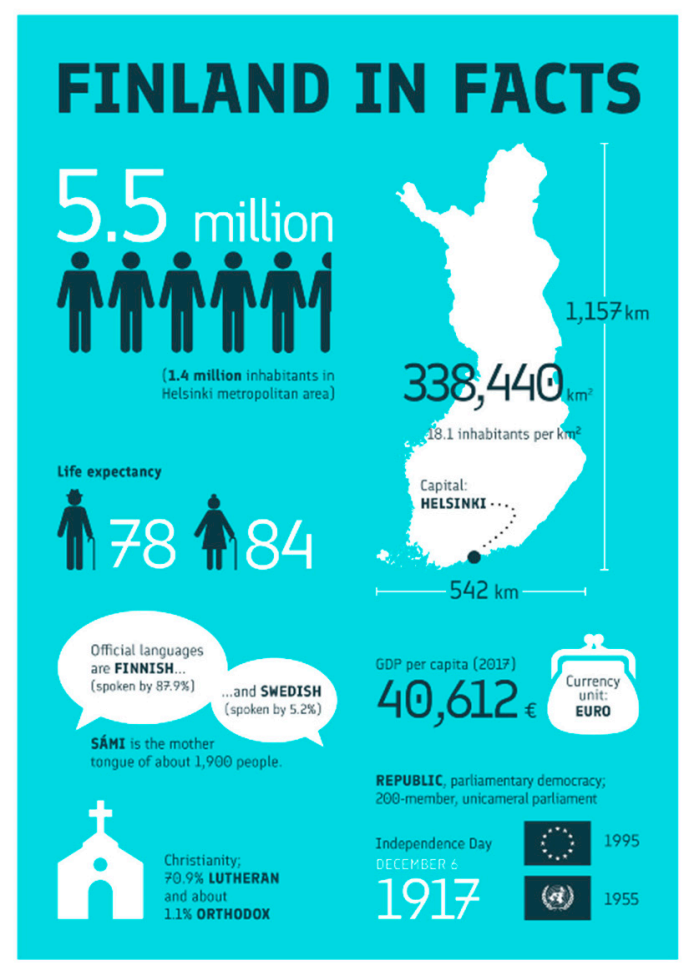

Figure 1. Facts about Finland (This is Finland 2018).

This geographical scattering, as well as the low population density, certainly has a major effect on the increasing use of online learning. Educational institutions are located in bigger towns and, in order to make it possible for more people to participate in education, versatile ways to implement online learning have been developed. Online learning possibilities also enable diverse combinations of work and study. Online learning can improve the motivation of students because studying can be self-paced. In other words, you can learn where and whenever you want. However, online learning demands a higher degree of autonomy, self-discipline and organizational skills. Neumeier (2005) found out that, in order to support the participation rate of the students, the course should be clearly structured, in relation to, for example, the sequencing and methodological choices. According to Official Statistics of Finland (OSF 2018a), 98\% of the population aged 16-64 use the Internet and 90\% use the Internet many times a day.

Due to obtaining very good PISA results at the beginning of the 21st century, Finland and its education system have been a point of interest among the actors working in the field of education worldwide. PISA stands for the Programme for International Student Assessment, which administers the testing of 15-year-old students all over the world in key school subjects (OECD 2018a). The program was established by the Organisation for Economic Co-operation and Development (OECD). Burg (2018) highlights some differences between Finland and the USA in relation to education and circumstances affecting the learning abilities of children. Two themes that undoubtedly have an impact on the realization of learning are the number of children living in poverty (Finland 5.3\% and US 33\%) and the number of non-native language speakers (Finland 10\% and US 20\%) (Burg 2018). Education in Finland is free at all levels of education. Thus, studying is possible in all phases of life and lifelong learning has been an important principle for decades. 
In Finland, there are two types of higher education institutions: universities and universities of applied sciences (also known as Vocational Universities or Polytechnic Universities). The Ministry of Education and Culture steers and finances the activities and promotes the quality of higher education institutions. In order to develop the quality of education, the Ministry has listed several themes to be considered, e.g., teaching methods, learning environments, competence of teachers, digitalization, cooperation between institutions, flexibility in studies and recognition of prior learning. One important target is to identify the competence and educational needs of immigrants and to improve their chances of getting into the labor market. (Ministry of Education and Culture 2018).

A process to build a vision for the Finnish higher education and research in 2030 has been ongoing for one year. The target of the process is to create a future scenario for developing the Finnish higher education system. According to this vision, "flexible and personalized study paths and degrees will enable lifelong learning in different life situations. Digitalization and openness will renew teaching, learning, research and innovation activities as well as higher education institutions and will open up new channels for effectiveness." (Ministry of Education and Culture 2017).

The affiliation of the authors of this article is South-Eastern Finland University of Applied Sciences (Xamk). Xamk is the 5th largest university of applied sciences in Finland and it operates in four towns: Kotka, Kouvola, Mikkeli and Savonlinna. The distance between the farthest campuses (Kotka and Savonlinna) is $260 \mathrm{~km}$ (Figure 2).

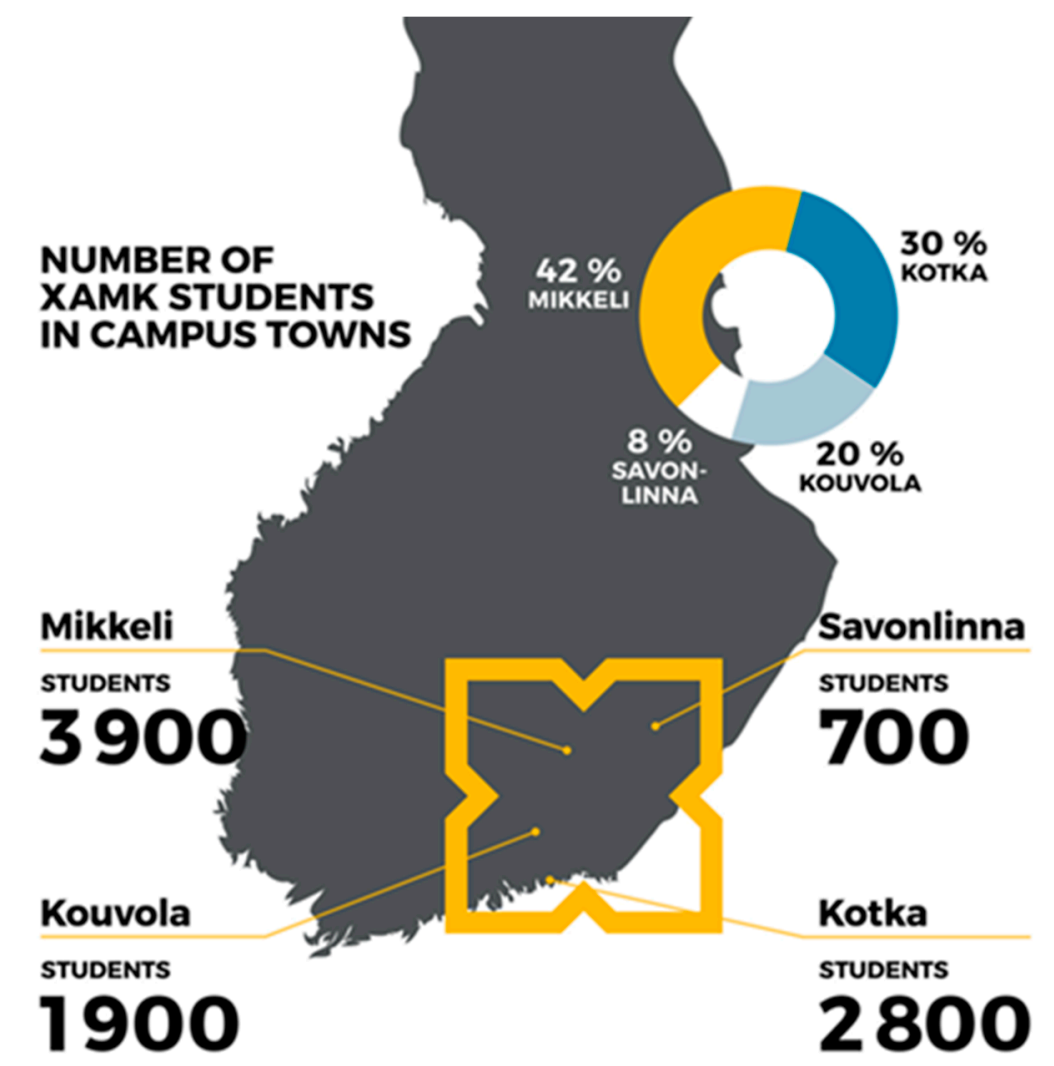

Figure 2. South-Eastern Finland University of Applied Sciences, an organization with geographical challenges (Xamk 2018).

The vision of Xamk includes similar themes and targets to those of the national vision (see Ministry of Education and Culture 2017). The Strategy 2018-2030 focuses on the following themes: education and research that are independent of time and place, identification of future professions and developing the education accordingly, development of digital learning environments and new technological means of teaching, individual learning paths and international competence of students and staff. (Strategia 2018-2030 2017). 


\section{Preparatory Studies for Immigrants}

Finnish HEIs are responsible for organizing preparatory courses for immigrants in higher education (Act of Polytechnics 14.11.2014/932 2014, § 10). These courses should be targeted at persons who come from an immigrant background and who benefit from the development of learning abilities and language skills. However, the supply of preparatory courses, application processes, content and scope vary from one institution to another (Lepola 2017).

\subsection{National Project to Standardize Preparatory Studies}

The project "Getting ready—A higher education preparatory program for immigrants" (2018-2019) develops education by preparing national recommendations for preparatory studies. The project develops the regional implementations of preparatory courses, operated by HEIs all over the country. However, the main focus is on the joint online implementations in which a versatile selection of digital methods is used. (Getting Ready 2017).

The project is coordinated by Metropolia, which is the biggest University of Applied Sciences in Finland and operates in the Helsinki region. However, the project work reaches all over Finland since there are altogether nine Finnish HEIs and nearly 30 specialists working for the project. (Getting Ready 2017; Metropolia 2017). Both authors are experienced language teachers and they are also used to teaching online: Sirpa Juusola is a Senior Lecturer in the English and German languages, and in this project her responsibility is to participate in planning, creating and teaching English courses called "English for Health Care and Social Services" and "English for Higher Education Studies". Juusola also operates as a tutor and teacher of one student group. Miia Karttunen is a Senior Lecturer in the Finnish language (L1 and L2) and Communication. Karttunen participates in the planning and implementation of Finnish courses "Business and Finnish as a Second Language" and "Higher Education Studies and Finnish as a Second Language". (Figure 3).

The project is funded by the Ministry of Education and Culture. The funder expects that the project will be able to create common recommendations and practices. The project is based on social and demographic demands: Finland is a country with a decreasing population. The proportion of working-age people is continuously decreasing (OSF 2018b). Of course, there is a growing number of immigrants in Finland (OSF 2017; Honko and Mustonen 2018) but finding a job in Finland is not easy without proper skills in the Finnish language or other skills needed to study efficiently.

The aim of the current project is to increase the ability of immigrant people to enter higher education and, after that, working life. Ministry of Education and Culture (2018) states in their policy and development in higher education and science: "The higher education institutions exercise foresight and help regenerate society, culture and working life and make sure the required highly educate workforce is available." Higher education should be equally available for all, but - perhaps surprisingly—unequal opportunities for education is a growing problem in OECD countries (OECD 2018b). The preparatory program is one step towards increasing the empowerment of immigrants by giving them tools for getting on career paths through higher education. 


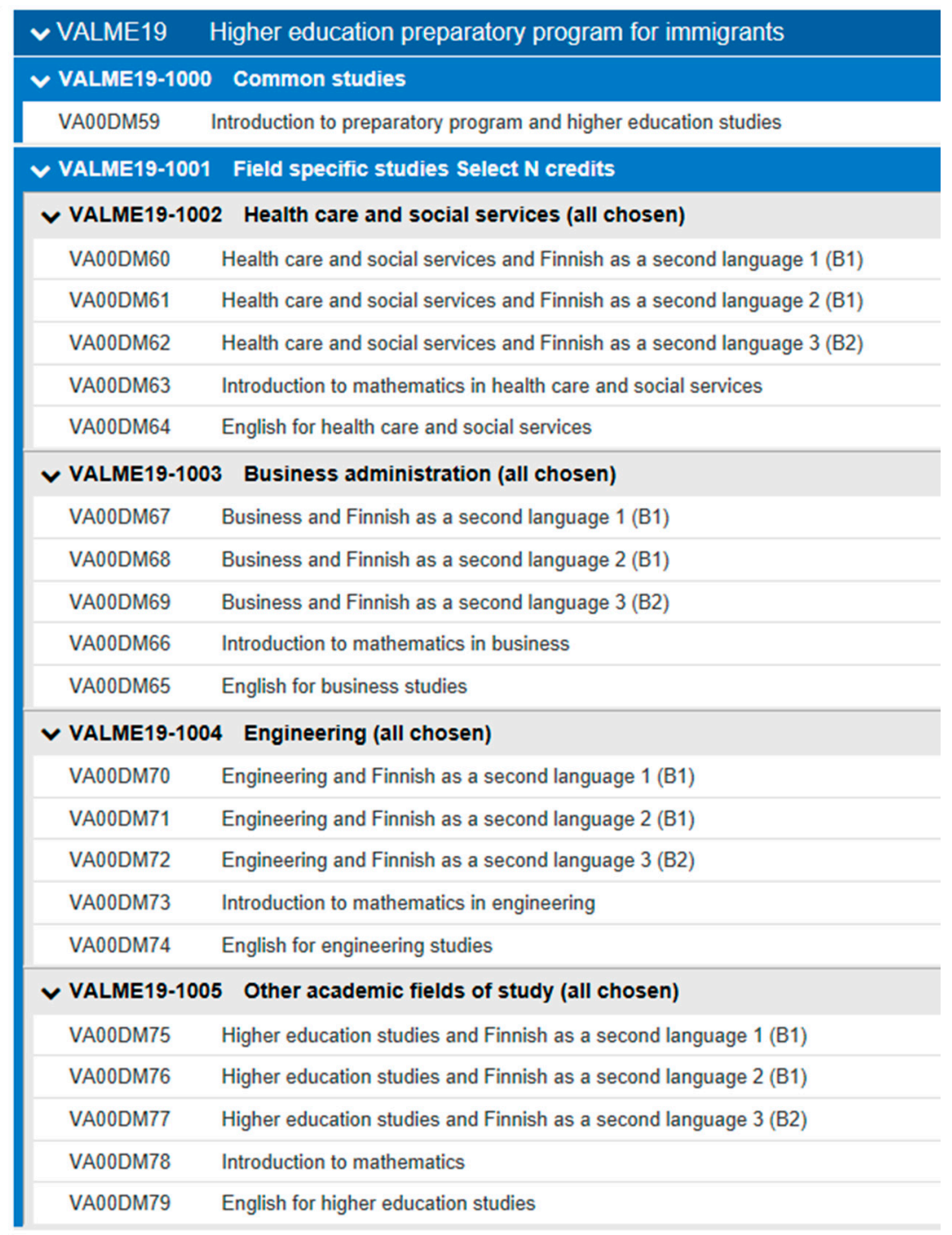

Figure 3. The study plan for the higher education preparatory program for immigrants (Xamk 2018).

\subsection{Content and Schedule of the Program}

Several studies (see Paakkinen 2016; Nieminen 2015) have suggested that language skills are essential when a person wants to enter the Finnish higher education system or a specialist-level occupation. English is widely spoken in Finland, but it is common that fluent Finnish skills (CERF level B2 or better; CERF refers to Common European Framework of Reference for Languages 2001, published by Council of Europe) are required as well. For that reason, Finnish language courses play a major role in the preparatory program. Finnish studies are intertwined with studies from three different professional fields (Health Care and Social Services, Business Studies, Engineering). There is also a fourth option for general higher education studies, without a professional specialization. In addition, the preparatory program offers courses in English, mathematics and common learning skills for higher education studies, including digital skills. As Figure 3 shows, there is a great variety of courses but only the first course, "Introduction to Preparatory Program and Higher Education Studies" is compulsory for all students in the preparatory program.

The other courses should be selected according to the professional field. Each student has a study plan which consists of six courses. The extent of each course is 5 ECTS (European Credit Transfer and Accumulation System), and the whole program is 30 ECTS which means full-day studies for six months. All courses will be conducted digitally, and students are able to join the studies online 
from anywhere. Only the orientation day is planned to take place in Helsinki at the beginning of the studies. After meeting in Helsinki at the beginning of April, the students, teachers, tutors and student counsellors meet online.

The project "Getting ready-A higher education preparatory program for immigrants" started at the end of 2017. During 2018, we have been studying the needs and possibilities for the preparatory program, developing the national recommendations and preparing the study and implementation plans, getting to know different digital tools, online pedagogy and approaches for online tutoring. Above all, the cooperation between language specialists from different HEIs has deepened enormously. The partially digital entrance tests were organized at the beginning of February 2019. The first online implementation runs from April 2019 to September 2019, and the results of the project will be evaluated and reported for the Ministry by December 2019.

\section{Feedback Creating Quality}

Quality is a concept with many meanings. It is difficult to give an exact and universal definition of it. Fortunately, quality in higher education is a concept which has drawn attention in recent years. For example, the European Association of Institutions in Higher Educations EURASHE organizes conferences and publishes reports frequently (Bollaert 2014).

Finnish HEIs are committed to quality work. For example, in our home organization Xamk, each member of the community is responsible for the development of his/her own activities and the quality culture arises from individual and collective development. Maintaining quality demands systematic work in data collecting, information sharing, clarifying responsibilities, standardizing practices, spreading good practices and ensuring transparency, reliability and confidentiality. These quality processes extend through the whole organization, management, research staff, teachers and students. (Quality Management at Xamk 2018).

Xamk's quality does not grow or stay without continuous development work. This ongoing and never-ending development can be simplified with the help of Deming's PDCA cycle which is a continuous quality improvement model: the cycle starts from planning (P), continues with doing (D), checking (C) the results and acting (A) for the improvement based on the previous steps. After this, the Deming's cycle starts again from the beginning. This model is widely used in the quality processes of HEIs. (Moen and Norman 2010). When planning and piloting a course, the Deming's cycle helps the teacher to maintain quality by following the steps:

- Plan the course

- Pilot the course

- Check how the piloting succeeded

- Do the necessary improvements

- Implement the course again in an improved form.

The Getting ready project (see Section 3) is about planning, doing and checking, i.e., Deming's steps P, D and C. The last step A 'act' will take place after the project work has been completed. Hopefully, systematic development will continue after that as well.

Related to Deming's step C, checking, Finnish HEIs have systematic procedures. If management or an individual teacher want to know how the course succeeded, it is possible to collect data via a feedback inquiry. Xamk has standardized, digital course feedback forms and quite a clear process for sending inquiries to students and for later analyzing the received feedback. The Xamk students are asked to give feedback on the courses systematically and frequently, which gives teachers an opportunity to have information which is valuable when improving the courses (Quality Management at Xamk 2018). The feedback should be targeted correctly. Patton $(2012,2013)$ offers a U-FE check list which helps to target feedback questions and guarantee the feedback is as beneficial as possible. If students give feedback but notice later that their feedback is not used for the improvement of the course, students will easily lose their motivation. (Leckey and Neill 2001; Chadna and Frick 2011). 
When students give feedback, teachers can use it for improving the course. If we change the direction of feedback, and the teacher is the one who gives feedback for a student, he/she gets the opportunity to improve his/her course performance. Giving feedback is also one form of evaluation or assessment. The evaluation process includes observing the learners' existing strengths, as well as conclusions and recommendations for future development. Evaluation or assessment are not synonymous with criticism or judgement. Evaluation can take place before, during or after the course. (Virtanen 2007).

Feedback should appear as a continuous, developmental and encouraging dialogue between a student and a teacher and it should be carried out in different ways, e.g., individual or generic feedback, peer feedback or self-evaluation. (Audit Manual for Higher Education Institutions 2018-2024 2017).

\section{Quality in Online Learning}

Several current projects in Finland focus on online learning. One of them is the eAMK project, which is funded by the Ministry of Education and Culture for 2017-2020. Its most important target is to create a shared offering of digital courses that is available for all universities of applied sciences. In order to broaden the selection of online courses, a coaching program will be implemented to increase staff competence on digital pedagogy. (eAMK Project 2018a).

With a similar viewpoint of online learning, the Getting ready! project (Section 3) has utilized resources and outcomes of the eAMK project. First, the eAMK project provides coaching in digital course planning for the specialists from the Getting ready! project. Second, the quality criteria for online implementation of the courses that have been developed in the eAMK project will be utilized in the Getting Ready! project as well as in Finnish online course design generally.

In the quality criteria, creating a new online course has been discussed from the following viewpoints: (1) Target group and users, (2) Learning objectives, learning process and pedagogical solution, (3) Assignments, (4) Contents and materials, (5) Tools, (6) Interaction, (7) Guidance and feedback, (8) Evaluation, (9) Development, (10) Usability and visuals, (11) Support services. (eAMK Project 2017).

Target group and users include considering the starting level requirements of the course and informing the students about them. In some cases, the starting level can be tested in order to choose the students with the adequate knowledge for completing the course. The teacher should also know the number of participants and take it into account in the course.

Learning objectives, learning process and pedagogical solution include defining the learning objectives related to field-specific and generic competences, working life orientation, and internationalization. The pedagogical solutions are chosen to help the students to reach the learning objectives.

Assignments should help the students to reach the learning objectives and to take real working life situations into consideration. The target, schedule and evaluation criteria of the assignments should be clear. The assignments should be suitable for online learning.

Contents and materials should provide the students the possibility to combine previous and new information and select the most appropriate material. The materials should be up-to-date, reliable and legally accessible.

Tools in the course have been chosen to support the achievement of the learning objectives. The tools should be free and secure and there should be clear instructions for using or downloading the tools. The course description includes the information about the equipment and application requirements.

Interaction during the course should be implemented using easy modes of interaction, e.g., Skype, Adobe connect. The purpose of interaction is to support the achievement of the learning objectives.

Guidance and feedback should be available in a timely manner and during the whole course. The implementation methods, timetable and responsible persons should be clearly presented on the 
online platform. The possibility for the students to ask questions and give feedback should be available. Analysis tools of the online platform can be used for monitoring the progress of the students.

Evaluation should be implemented using versatile methods, such as peer evaluation, self-evaluation and automatic tests. The evaluation subjects are related to the learning objectives. The evaluation process is presented in the course description.

Development of the course should be continuous. All aspects of the course (e.g., methods, contents, online tools, learning objectives) should be assessed and developed. Feedback is collected from the students and the teachers, and the course is developed on the basis of the received feedback.

Usability and visuals include considering at least the following themes: structure and progress of the course, naming of the files and folders, unified style, readability (font, colors), accessibility of text formats and visual elements (pictures, videos), overall accessibility (different types of terminal devices) and security.

Support services should be available for both the students and the teachers. Information about the services and their schedule is clearly presented on the online platform.

On the basis of these criteria, the project participants have developed a tool for evaluating online courses (eAMK Project 2018b). The tool is free and available for anyone at https://eamk.fi/en/coursesoffering/evaluation/. This tool will be used to steer our planning of the online preparatory courses for immigrants.

Similar criteria for designing online courses have been presented by Vai and Sosulski (2011). They have created a practical but theory-based application for designing an online course, especially for higher education purposes. Vai and Sosulski's guidelines for successful online course design suggest that an online course meets the quality demands when the following principles have been taken into account: (1) The graphical design is clear, i.e., the lay-out supports readability and visual and auditive elements are used to improve clarity, (2) The language is clear, the writing style is brief and the tone is supportive, (3) The course offers real-world multimodal examples and multiple learning resources and 4) The course has a clear structure with chapters. When planning new online courses or updating old ones, it is useful to find and study guide books in this field. For example, Meskill and Anthony (2015) offer a pragmatic overview on teaching languages online.

In Section 6, we choose for closer study some learning principles that should be taken into account in the joint online implementations. We examine these principles by utilizing the quality criteria introduced in Section 5. This study is important for us because we need to decide how to follow the quality criteria while building courses for the preparatory program.

\section{Ensuring Quality in the Preparatory Training Course}

The project introduced above, "Getting ready-A higher education preparatory program for immigrants" implements the first online preparatory course in April-September 2019. The planning phase of the different courses included in the entity occurs at the end of the year 2018 and at the beginning of the year 2019 .

As framed in Section 2, quality in online learning has been an issue that has been considered in many recent research studies. We apply this theoretical framework in order to create an online implementation with high quality. However, our focus is on pragmatic features. On the basis of our earlier online teaching experiences, we chose three important online learning principles or challenges to be considered more carefully in the planning of our courses (Finnish and English). These principles are the teacher availability, students' expectations and feedback and evaluation. We examined these principles using the quality criteria introduced in the previous section in order to solve and foresee the possible problems in the course implementation.

\subsection{Teacher Availability}

When comparing contact courses to online courses, one of the most significant differences is the form of communication. In contact courses, the students see the teacher in live meetings according to 
the course timetable but, in contrast, there are no live meetings for online courses. The teacher and the student don't share the same physical space and teaching and learning are asynchronous (see Vai and Sosulski 2011). This difference sets versatile challenges on the form and quality of interaction in online courses.

According to the quality criteria for online implementations, interaction during the course should be implemented using modes and tools that support learning and reaching the learning targets. In our preparatory course, the learning environment is Moodle and in weekly meetings with the students we will use Skype for Business. Quite often online courses consist of material and tasks and there are no live online sessions between the teacher and the students. In our implementations the weekly online meetings support the students in their learning and provide the ability to practice the learning objectives.

It is also important that the students know when and how they can contact the teacher. According to the quality criteria, the schedule of the course should be clearly presented on the online platform. This schedule should also include the information about the teacher availability and the teacher's contact information.

In our preparatory courses we will create video lectures about important advice related to the course (e.g., schedule, assignments). The lectures will be available on the online platform and they allow the students to review the course information as many times as they need to in order to comprehend any essential matters.

\subsection{Students' Expectations}

The individual learning objectives of students typically vary a great deal. One student wants to learn the basics of a new language while the other needs credits in order to ensure his or her study grant. Thus, the students' expectations can be diverse. From the preparatory course students' point of view, the learning objective for most of them is to develop the skills needed for applying to higher education. Presumably their motivation will be good and expectations will be high.

To meet the students' expectations, all parts of the quality criteria for online implementations should be considered. However, different students appreciate different qualities of courses. In any case, on the basis of the long online teaching experience of the authors, the most important qualities are a clear structure and schedule. It is essential to know what to do and when. According to the quality criteria, the assignments of the course should be clearly introduced on the online platform in relation to their purpose, schedule and evaluation criteria.

In order to meet the course participants' individual expectations, the course should be implemented so that all students get the possibility to use their strengths and to develop their weaknesses. At the end of the course all participants should feel that personal development has occurred and increased competence has been developed.

Meeting the individual expectations of the students is a problematic issue. While the group size grows, arranging time for meeting the students individually becomes challenging. In this project, we have a chance to teach rather small groups of about 20 students. However, one goal of online courses is to offer study possibilities for a massive audience. In order to enable learning for different kinds of learners and to maintain the quality, the use of versatile tools and endless imagination are needed.

\subsection{Feedback and Evaluation}

Feedback is a two-way dialogue between the teacher and the students of the course. The quality criteria for online implementations also supports this principle. This two-way interaction should be made possible on the online platform. In our preparatory courses there are many ways to carry out interaction, e.g., Skype-sessions and discussion areas.

Evaluation is usually one of the most challenging parts of course implementations. The different sections of the evaluation process in an online course should be clearly described on the online platform. These sections include the subjects, the method, the criteria and the schedule of the evaluation. 
The criteria should be based on the learning objectives of the course so that the students are able to reflect their learning themselves, too.

Feedback and evaluation are also matters of self-confidence. In order to support students to utilize their strengths in learning and to overcome their learning challenges, the ways to give feedback and to implement evaluation should be carefully considered. Creating an appreciative atmosphere in the course starting from the beginning plays a crucial role in relation to the learning results.

\section{Conclusions}

To conclude our article, we wanted to use the universal SWOT analysis model to crystallize the present state and the future of the pilot online implementation. Strengths and weaknesses describe the present state of the project and its actors as well as the everyday life in HEIs in Finland. Opportunities and threats describe the future thoughts about the pilot courses. We compiled our main perceptions in Table 1.

Table 1. SWOT analysis related to the online implementation.

STRENGTHS

- $\quad$ Qualified and experienced teachers participating in the project

- Content competence of the teachers is comprehensive

- $\quad$ Online learning very common in HEIs

- Steady support from the Ministry of Education and Culture when creating a new model for immigrants' preparatory program

\section{WEAKNESSES}

- Timetable challenges part of everyday life

- Excessive workload

- Fragmented duties of the teachers

\section{OPPORTUNITIES}

- Pilot implementation doesn't need to follow the earlier "rules"

- For teachers, the possibility to learn new pedagogical approaches and use new teaching and learning methods

- $\quad$ Students' need to learn increases their motivation

- $\quad$ Best practices from all participating institutions can be utilized

\section{THREATS}

- $\quad$ Digital challenges of both the teachers and the students

- Heterogeneous groups (varying digital, learning and language skills)

- $\quad$ Summer vacation $->$ guidance and feedback during this time

- Missing face-to-face interaction

Finally, the two most relevant themes to be taken into consideration while creating online courses are the encounter and the course description. A satisfied student knows the answers to the following questions: What should I do? When should I do something? Who supports me during my studies?

When the course and its pedagogical, supportive and technical arrangements are working faultlessly, the offered value meets the student's expectations. In this case, the quality criteria are achieved. If the course manages to go over the quality criteria, we have succeeded in offering some added value (Pulkkinen 2016). The Getting ready project will be completed at the end of 2019, and then we will be able to analyze whether or not we have managed to offer the preparatory program in such a way that the quality criteria were followed or even exceeded. When offering new services, in this project a new model for the preparatory education, it is critically important to gain a good reputation as a reliable education provider; that would help us to start a positive spiral in Finnish higher education for immigrants. After piloting the preparatory program, we will be able to examine our product and customer satisfaction and continue the development with a service design conception.

Author Contributions: Conceptualization, methodology, software, validation, formal analysis, investigation, resources, data curation, writing-original draft preparation, writing-review and editing, visualization, supervision, M.K. and S.J.; project administration, funding acquisition, M.K. 
Funding: This research was funded by the Ministry of Education and Culture, grant number OKM/47/529/2017.

Conflicts of Interest: The authors declare no conflict of interest.

\section{References}

Act of Polytechnics 14.11.2014/932. 2014. Finlex Data Bank, Finnish Ministry of Justice. Available online: https://www.finlex.fi/fi/laki/ajantasa/2014/20140932 (accessed on 7 December 2018).

Audit Manual for Higher Education Institutions 2018-2024. 2017. Finnish Education Evaluation Centre. Publications 21. Available online: https://karvi.fi/app/uploads/2017/02/FINEEC_Audit_manual_for_higher_ education_institutions_2018-2024_FINAL.pdf (accessed on 8 December 2018).

Bollaert, Lucien. 2014. Manual for Internal Quality Assurance in Higher Education-With a Special Focus on Professional Higher Education. Brussels: European Association of Institutions in Higher Educations EURASHE, ISBN 978-3-8183-0721-9.

Burg, Carol A. 2018. Finnish Education in the 21st Century: Paradoxes and Visions. Inquiry in Education 10: 8. Available online: https://files.eric.ed.gov/fulltext/EJ1180740.pdf (accessed on 8 December 2018).

Chadna, Rajad, and Theodore W. Frick. 2011. Dependability of College Student Ratings of Teaching and Learning Quality. Paper presented at the annual conference of the American Educational Research Association. Available online: https:/www.indiana.edu/ \{\}tedfrick/aera2011/AERA2011ChadhaFrickTALQpaper_ FinalVersion.pdf (accessed on 13 December 2018).

Common European Framework of Reference for Languages. 2001. Council of Europe, Modern Languages Division. Strasbourg. Available online: https://rm.coe.int/1680459f97 (accessed on 9 December 2018).

eAMK Project. 2017. Quality Criteria for Online Implementations. Available online: https://www.eamk.fi/en/ courses-offering/quality-criteria/ (accessed on 10 December 2018).

eAMK Project. 2018a. Available online: https://eamk.fi/en/project2/ (accessed on 11 December 2018).

eAMK Project. 2018b. Online Implementations Evaluation Tool. Available online: https://eamk.fi/en/coursesoffering/evaluation/ (accessed on 12 December 2018).

Fontaine, Gary. 2002. Presence in "Teleland". In Handbook of Online Learning. Innovations in Higher Education and Corporate Training. Edited by Kjell Erik Rudestam and Judith Schoenholtz-Read. Thousand Oaks: Sage, pp. 21-52, ISBN 0-7619-2403-5.

Getting Ready. 2017. Getting Ready-A Higher Education Preparatory Program for Immigrants. Metropolia University of Applied Sciences: Research, Development and Innovation. Available online: https://www.metropolia.fi/en/research-development-and-innovation/all-projects/getting-ready-ahigher-education-preparatory-program-for-immigrants/ (accessed on 8 December 2018).

Hong, Kwang Hee, and Keiko K. Samimy. 2010. The Influence of L2 Teachers' Use of CALL Modes on Language Learners' Reaction to Blended Learning. CALICO Journal 27: 328-48. [CrossRef]

Honko, Mari, and Sanna Mustonen. 2018. Kielistä kielitietoon. In Tunne kieli. Matka Maailman Kieliin ja Kielitietoisuuteen. Edited by Mari Honko and Sanna Mustonen. Helsinki: Finn Lectura, pp. 18-31, ISBN 978-951-792-923-3.

Leckey, Janet, and Neville Neill. 2001. Quantifying Quality. Importance of Student Feedback. Quality in Higher Education 7: 19-32. [CrossRef]

Lepola, Laura. 2017. Ammattikorkeakoulujen Maahanmuuttajille Järjestämä Korkeakouluopintoihin Valmentava Koulutus Vuosina 2010-2017. Kansallinen Koulutuksen Arviointikeskus. Julkaisut 2017: 15. Available online: https://karvi.fi/app/uploads/2017/06/KARVI_1517.pdf (accessed on 14 December 2018).

Lim, Doo Hun, Michael L. Morris, and Virginia W. Kupritz. 2007. Online vs. Blended Learning: Differences in Instructional Outcomes and Learner Satisfaction. Journal of Asynchronous Learning Networks 11: $27-42$. Available online: https://files.eric.ed.gov/fulltext/EJ842695.pdf (accessed on 16 April 2019). [CrossRef]

Meskill, Carla, and Natasha Anthony. 2015. Teaching Languages Online, 2nd ed. MM Textbooks 12. Bristol: Multilingual Matters.

Metropolia. 2017. Metropolia University of Applied Sciences-Expertise and Insight for the Future. Available online: https://www.metropolia.fi/en/about-us/ (accessed on 8 December 2018).

Ministry of Education and Culture. 2017. Vision for Higher Education and Research in 2030. Available online: https://minedu.fi/en/vision-2030 (accessed on 9 December 2018). 
Ministry of Education and Culture. 2018. Policy and Development in Higher Education and Science. Available online: https://minedu.fi/en/policy-and-development-in-higher-education-and-science (accessed on 10 December 2018).

Moen, Ronald D., and Clifford L. Norman. 2010. Circling back. Clearing up myths about the Deming cycle and seeing how it keeps evolving. Quality Progress 43: 22-28. Available online: http://www.apiweb.org/circlingback.pdf (accessed on 15 December 2018).

Neumeier, Petra. 2005. A closer look at blended learning-Parameters for designing a blended learning environment for language teaching and learning. ReCALL 17: 163-78. [CrossRef]

Nieminen, Tarja. 2015. Ulkomaalaistaustaisten ei-Työllisten Työnhaku on Aktiivisempaa kuin Suomalaistaustaisilla-Kielitaito Suurin este Työllistymiselle. Official Statistics of Finland. Available online: https://www.stat.fi/tup/maahanmuutto/art_2015-12-17_002.html (accessed on 17 December 2015).

OECD. 2018a. Program for International Student Assessment. Available online: http://www.oecd.org/pisa/ (accessed on 8 December 2018).

OECD. 2018b. Education at a Glance. OECD Indicators 2018. Available online: http://www.oecd.org/education/ education-at-a-glance/ (accessed on 11 September 2018).

Oh, Eunjoo, and Doohun Lim. 2005. Cross Relationships between Cognitive Styles and Learner Variables in Online Learning Environment. Journal of Interactive Online Learning 4: 53-66.

OSF. 2017. Official Statistics of Finland. Population Structure 2017. Available online: https://stat.fi/tup/suoluk/ suoluk_vaesto_en.html\#populationstructure31december (accessed on 10 December 2018).

OSF. 2018a. Official Statistics of Finland. The Internet is Used ever More Commonly with a Mobile Phone-Even for Shopping. Available online: http://tilastokeskus.fi/til/sutivi/2018/sutivi_2018_2018-12-04_tie_001_en.html (accessed on 4 December 2018).

OSF. 2018b. Official Statistics of Finland. Population Projection. Available online: http://www.stat.fi/til/vaenn/ 2018/vaenn_2018_2018-11-16_tie_001_en.html (accessed on 16 November 2018).

Otte, George, and Meg Benke. 2006. Online learning: New models for leadership and organization in higher education. Journal of Asynchronous Learning Networks 10: 23-31. Available online: https://www.cite.hku.hk/ events/doc/2006/v10n2_2otte.pdf (accessed on 15 April 2019). [CrossRef]

Paakkinen, Erika. 2016. Maahanmuutto ja Julkisen Sektorin Työelämä. Keva. Available online: https://www.keva.fi/globalassets/2-tiedostot/ta-tiedostot/tyoelamapalvelut/tutkimus_maahanmuutto_ja_ julkisen_sektorin_tyoelama_keva.pdf (accessed on 14 December 2018).

Pardere, Parlindungan. 2012. Blended Learning for ELT. Journal of English Teaching 2: 165-78.

Pardere, Parlindungan. 2019. Pre-Service EFL Teachers' Perception of Blended Learning. Journal of English Teaching 5: 1-14. Available online: http://ejournal.uki.ac.id/index.php/jet/article/view/955 (accessed on 28 February 2019).

Patton, Michael Q. 2012. Essentials of Utilization-Focused Evaluation. Thousand Oaks: Sage Publications, ISBN 978-1412977418.

Patton, Michael Q. 2013. Utilization-Focused Evaluation (U-FE) Checklist. Available online: http://www.wmich. edu/sites/default/files/attachments/u350/2014/UFE_checklist_2013.pdf (accessed on 28 May 2018).

Pulkkinen, Pekka. 2016. Creating an Added Value Services Model for the Apprenticeship Center of Itä-Uusimaa. Case Study. Master's thesis, Häme University of Applied Sciences, Hämeenlinna, Finland. Available online: http://urn.fi/URN:NBN:fi:amk-2016111416119 (accessed on 12 December 2018).

Quality Management at Xamk. 2018. South-Eastern Finland University of Applied Sciences. Available online: https://www.xamk.fi/wp-content/uploads/2016/06/Quality_management_at_Xamk.pdf (accessed on 13 December 2018).

Staker, Heather, and Michael B. Horn. 2012. Classifying K-12 Blended learning. Innosight Institute. Available online: https://files.eric.ed.gov/fulltext/ED535180.pdf (accessed on 13 April 2019).

Strategia 2018-2030. 2017. Kaakkois-Suomen Ammattikorkeakoulu (South-Eastern Finland University of Applied Sciences). Available online: https://www.xamk.fi/wp-content/uploads/2017/11/Xamk_Strategiaesite_ 23112017.pdf (accessed on 14 December 2018).

This is Finland. 2018. Finland in Facts. Available online: https:/finland.fi/facts-stats-and-info/finland-in-facts-2/ (accessed on 30 July 2018).

Vai, Marjorie, and Kristen Sosulski. 2011. Essentials of Online Course Design. A Standards-Based Guide. New York: Routledge, ISBN 139780203838310. 
Virtanen, Petri. 2007. Arviointi: Arviointitiedon luonne, tuottaminen ja hyödyntäminen. Helsinki: Edita, ISBN 978-951-37-4612-4.

Wang, Yuping, Xibin Han, and Juan Yang. 2015. Revisiting the Blended Learning Literature: Using a Complex Adaptive Systems Framework. Educational Technology E Society 18: 380-93.

Xamk. 2018. E-Service Peppi. Kouvola: South-Eastern Finland University of Applied Sciences.

(C) 2019 by the authors. Licensee MDPI, Basel, Switzerland. This article is an open access article distributed under the terms and conditions of the Creative Commons Attribution (CC BY) license (http://creativecommons.org/licenses/by/4.0/). 